\title{
The Bone Marrow Endosteal Niche: How Far from the Surface?
}

\author{
Eric Cordeiro-Spinetti, ${ }^{1}$ Russell S. Taichman, ${ }^{2}$ and Alex Balduino ${ }^{1,3 *}$ \\ ${ }^{1}$ Cell Technology and Biology Lab, Veiga de Almeida University, Rio de Janeiro 20270-150, RJ, Brazil \\ ${ }^{2}$ School of Dentistry, University of Michigan, Ann Arbor 48109-1078, Michigan, USA \\ ${ }^{3}$ Excellion Biomedical Services Lab, Petrópolis 25651-000, RJ, Brazil
}

\begin{abstract}
Hematopoietic stem cells (HSC) self-renewal takes place in the same microenvironment in which massive hematopoietic progenitor proliferation, commitment, and differentiation will occur. This is only made possible if the bone marrow microenvironment comprises different specific niches, composed by different stromal cells that work in harmony to regulate all the steps of the hematopoiesis cascade. Histological and functional assays indicated that HSC and multipotent progenitors preferentially colonize the endosteal and subendosteal regions, in close association with the bone surface. Conversely, committed progenitors and differentiated cells are distributed in the central and perisinusoidal regions, respectively. Over the last decade, many investigative teams sought to define which cell types regulate the HSC niche, how they are organized, and to what extent they interface with each other. System dynamics requires different stromal cells to operate distinct functions over similar HSC pools rather than a single stromal cell type controlling everything. Therefore, our focus herein is to depict the players in the endosteal and subendosteal regions, named the endosteal niche, a necessary step to better understand the interactions of the HSC within the niche and to identify potential targets to manipulate and/or modulate normal and malignant HSC behavior. J. Cell. Biochem. 116: 6-11, 2015. ๑ 2014 Wiley Periodicals, Inc.
\end{abstract}

KEY WORDS: BONE MARROW; HEMATOPOIETIC STEM CELLS; OSTEOBLAST; ENDOSTEUM; NICHE; IN VIVO

A fter birth, the bone marrow becomes the main site of blood cells production and hematopoietic stem cells maintenance for the individual's lifetime. Less than 0.5 percent of all nucleated cells in the bone marrow are hematopoietic stem cells (HSC) [Morrison et al., 1995; Serafini et al., 2007; Oguro et al., 2013]. Interestingly, HSC self-renewal takes place in the same microenvironment in which massive hematopoietic progenitor proliferation, commitment, and differentiation will occur. This is only made possible if the bone marrow microenvironment comprises different specific niches, composed by different stromal cells that work in harmony to regulate all the steps of the hematopoiesis cascade. Over the last decade, many investigative teams sought to define which cell types regulate the HSC niche, how they are organized, and to what extent they interface with each other. System dynamics requires different stromal cells to operate distinct functions over similar HSC pools rather than a single stromal cell type controlling everything. Therefore, our focus herein is to depict the players in the endosteal and subendosteal regions, a niche in which most of the HSC reside.

\section{NOT TOO FAR FROM THE SURFACE}

One of the first in vivo assays designed to determine the existence of hematopoietic progenitors in a given population was counting the numbers of colonies in the spleen 8-12 days after transplantation [Siminovitch et al., 1963; Till and McCulloch, 1963; Till et al., 1964]. When injected into the peripheral blood of lethally irradiated animals, a few hematopoietic progenitors migrate and colonize the spleen, in which they proliferate and give rise to colonies that can be observed visually. These progenitors, which we now know as shortterm hematopoietic stem cells, were identified as Colony-Forming Units-Spleen (CFU-S). A careful analysis of the colonies showed that progenitors proliferate and mature to fully differentiated normal cells. Ray Schofield (1978) questioned that the spleen connective tissue cells would then create the conditions to support a continued proliferation of these progenitors. This observation led him to hypothesize that progenitors/stem cells in the tissue would dwell in specific niches created by permissive stroma cells, which play crucial roles on the stem cells behavior. Cell behavior, in vivo and in vitro,

*Correspondence to: Alex Balduino, Laboratório de Biologia e Tecnologia Celular - LaBioTeC, Centro de Saúde Veiga de Almeida - CSVA, Praça da Bandeira, 149-5 andar, Rio de Janeiro 20270-150, RJ Brazil.

E-mail: balduino@uva.br

Manuscript Received: 20 August 2014; Manuscript Accepted: 22 August 2014

Accepted manuscript online in Wiley Online Library (wileyonlinelibrary.com): 28 August 2014

DOI 10.1002/jcb.24952 • (c) 2014 Wiley Periodicals, Inc. 


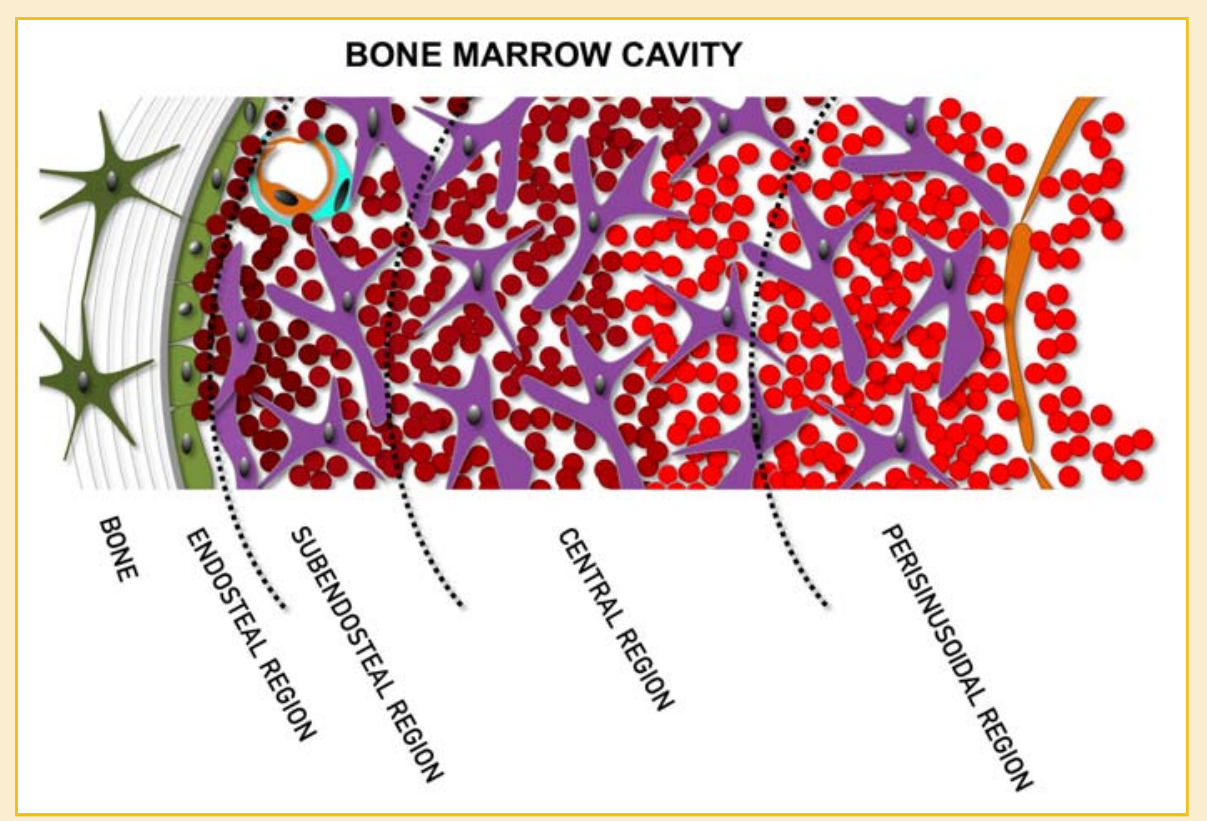

Fig. 1. Model of the bone marrow microenvironment subdivision as proposed by Lambertsen and Weiss [Lambertsen and Weiss, 1984]. Endosteal and subendosteal regions compose the endosteal niche, which harbors both the proliferative and quiescent HSC niches. This organization is easily adapted to the cavity of a long bone shaft, but a few anatomical arrangements must be considered when analyzing the bone marrow in the trabecular bone.

regardless its differentiation stage, is the result of a balance between intrinsic (gene expression) and extrinsic (niche) factors. To reside in a niche created by a specific stroma, hematopoietic cells must carry the adequate apparatus in order respond to the niche signals. Failing to express the right tools might result in an extremely different and unexpected behavior.

Almost all non-hematopoietic cells in the bone marrow microenvironment-osteoblasts, reticular cells, fibroblasts, neurons, adipocytes, endothelial cells-can be identified as a member of the stromal category and may play a critical role in hematopoiesis. Nonetheless, each stromal cell type likely resides in a distinct anatomical area in the marrow cavity, or in unique combination, to create different niches compatible to the intricate dynamic of the hematopoietic system. Long-term hematopoietic stem cells selfrenewal and committed progenitors proliferation and differentiation take place in the same microenvironment, but in very distinct niches - organized by distinct stromal cell types at different anatomical positions [Lord et al., 1975; Lambertsen and Weiss, 1984; Taichman and Emerson, 1994; Calvi et al., 2003; Zhang et al., 2003; Taichman et al., 1996, 2010; Balduino et al., 2005, 2012; Ding et al., 2012]. In a magnified view of the niche, even hematopoietic stem cells might require distinctive and/or combined interactions with similar albeit different stromal cell types regarding their quiescent or proliferative state.

How hematopoietic stem cells integrate cell intrinsic or extrinsic signals to remain quiescent, to self-renew, or to undergo differentiation remains unknown. Although several studies using genetic manipulated animals generate very rich data and demonstrate the contribution of very important molecules over hematopoietic stem cell behavior, they frequently fail to consider different stromal cell types, or even what the loss of a single cell type has on the other hematopoietic stroma, in such a defined niche.

The hematopoietic system is well organized in a hierarchical differentiation cascade [Seita and Weissman, 2010]. Long-term HSC originate short-term HSC, which then undergoes several commitments and massive proliferation, until reaching full differentiation. Each step in this cascade demands a different combination of cytokines, chemokines, extracellular matrix interactions and cellcell interactions, which are offered by different stromal cell types [Lord et al., 1975; Lambertsen and Weiss, 1984; Taichman and Emerson, 1994; Calvi et al., 2003; Zhang et al., 2003; Arai et al., 2004; Stier et al., 2005; Sugiyama et al., 2006; Taichman et al., 1996, 2010; Balduino et al., 2005, 2012; Ding et al., 2012]. The notion that different niches compose the bone marrow microenvironment was envisioned by Lord and colleagues [Lord et al., 1975]. In accordance with these data, another study has proposed that bone marrow cavity could be subdivided into at least four niches (Fig. 1): endosteal, subendosteal, central, and perisinusoidal [Lord et al., 1975; Lambertsen and Weiss, 1984]. Histological and functional assays indicated that HSC and multipotent progenitors preferentially colonize the endosteal and subendosteal regions, in close association with the bone surface. Conversely, committed progenitors and differentiated cells are distributed in the central and perisinusoidal regions, respectively [Lord et al., 1975; Lambertsen and Weiss, 1984; Taichman and Emerson, 1994; Nilsson et al., 2001; Arai et al., 2004; Kiel et al., 2005; Jung et al., 2006; Lo Celso et al., 2009].

Long-term and short-term HSC, as well as committed progenitors are easily identified by the expression of set of specific surface markers [Logan et al., 2012; Oguro et al., 2013]. Under physiological conditions, $20 \%-30 \%$ of the HSC are in a quiescent stage, and studies 
have shown that these slow-cycling HSC are found in association with endosteal osteoblasts [Kiel et al., 2005; Lo Celso et al., 2009; Nombela-Arrieta et al., 2013]. In in-vivo myelosuppressive models, HSC residing in contact with endosteal osteoblasts are preserved [Arai et al., 2004; Kiel et al., 2007]. Conversely, most of the fastcycling HSC are found in the perivascular neighborhood of the blood vessels distributed in the subendosteal region [Sugiyama et al., 2006; Kiel et al., 2007], and most of them are ablated in in-vivo myelosuppressive models.

The role of endosteal osteoblasts on the HSC maintenance and self-renewal was first proposed in vitro by Taichman and Emerson [1998], [Taichman and Emerson, 1994; Taichman et al., 1996] and later in vivo was established by others [Calvi et al., 2003; Zhang et al., 2003; Visnjic et al., 2004]. In transgenic animals, increased or decreased numbers of osteoblasts results in increased or decreased numbers of long-term HSC, respectively, without affecting any of the others hematopoietic categories in the bone marrow [Calvi et al., 2003; Zhang et al., 2003; Kuznetsov et al., 2004; Visnjic et al., 2004]. This is evidence that osteoblasts play a crucial role in HSC maintenance and behavior. Lambertsen and Weiss (1984) showed that most of the perivascular niches harboring HSC are distributed in the subendosteal region. In this perivascular niche [Arai et al., 2004; Kiel et al., 2005; Sugiyama et al., 2006], HSC reside on the abluminal side of bone marrow sinusoids, and are supported by the endothelial and perivascular reticular/mesenchymal cells. These perivascular stromal cells express high levels of CXCL12, a chemokine required for HSC maintenance and lodging [Jung et al., 2006; Sugiyama et al., 2006]. Most of the cells creating the proliferative niche express CXCL12. In-situ observation demonstrated that most of hematopoietic stem cells are concentrated in the trabecular zone of the marrow cavity, which also harbors high numbers of niche osteblasts, sinusoids, and CXCL12-positive reticular cells. Nonetheless, HSC maintenance by both endosteal and perivascular niches are, at least in part, mediated by Jagged-Notch and angiopoietin-1-Tie2 interactions [Calvi et al., 2003; Zhang et al., 2003; Arai et al., 2004; Sugiyama et al., 2006].

With direct or indirect contributions from osteoblasts and perivascular cells, published data support the fact that both proliferative and quiescent niches coexist in the marrow cavity and might even interact [Calvi et al., 2003; Zhang et al., 2003; Balduino et al., 2005; Wilson and Trumpp, 2006; Parmar et al., 2007; Taichman et al., 2010]. Endosteal bone-lining cells, at least most of them, are fully committed osteoblasts, as demonstrated by in vitro and in vivo assays [Balduino et al., 2005, 2012; Taichman et al., 2010]. In an intimate interaction with the endosteal cells, 2-3 layers of reticular/noncommitted mesenchymal cells will occupy the subendosteal region. Two very distinct stromal populations [Balduino et al., 2005, 2012; Taichman et al., 2010] that, due to their close range, are usually identified as in one niche. Our main purpose is to draw reader's attention to the fact that endosteal and subendosteal stromal derived cells can no longer be identified as a common stroma from a singular endosteal niche. The two regionsendosteal and subendosteal-can be considered as part of one niche, but stroma from this niche is far from being singular.

The cellular fraction of the endosteum is enriched in fully committed osteoblasts spread along the inner bone surface. These osteoblasts and all cells from the "reticular" fraction derive from a common progenitor, named mesenchymal stem cell, which is known to colonize the bone marrow during osteogenesis as blood vessels invade the cartilage mold [Nakamura et al., 2010]. Data from our group and others [Taichman, 2005; Nakamura-Ishizu and Suda, 2013; Morrison and Scadden, 2014] suggest that at least three types of stromal cells can be identified in the niche: osteoblasts, subendosteal perivascular reticular cells, and subendosteal nonperivascular reticular cells, each of which play distinct roles on hematopoietic stem cells behavior and niche creation, and must be considered as well. These cells share a few markers [Nakamura et al., 2010], mostly regarding the osteogenic lineage, which may not reflect the real effect of specific factors due to stromal population overlapping when studying genetically manipulated animals.

Regardless their origins, stromal cells engaged in the osteogenic differentiation cascade express Runx2 [Ducy et al., 1997; Komori et al., 1997; Stein et al., 2004]. This transcription factor is a member of the runt homology domain family and its function is essential to skeletogenesis, whereas in its absence no hyperthrophic chondrocytes and osteoblasts are generated during embryo development [Komori et al., 1997]. Runx2 was once indicated as skeletal tissue master gene. However, different transcription factors, extracellular matrix proteins and surface molecules will be necessary to complete the whole differentiation cascade. Close to the bone surface, all endosteal cells in the monolayer express Runx2. It is expected that cells in the subendosteal region also express Runx2, except perivascular progenitors.

The second step towards the osteogenic lineage is the expression of Osterix (also known as Sp7), another very important transcription factor, which is genetically downstream of the Runx2 [Ducy et al., 1997]. Osterix is expressed not only by osteogenic cells, but also prehypertrophic chondrocytes and a subset of stromal cells. Its expression is also essential to the osteogenic differentiation, whereas Osx-null mice lack bone tissue. In Osx-null mice, the expression of Runx2 is maintained, but the expression of other osteoblast specific markers is dramatically reduced or even undetected [Nakashima et al., 2002]. In these animals, osteogenesis is not completed since mesenchymal cells are unable to differentiate osteblasts. 0 sx + cells are considered pre-osteoblasts and they begin to express a set of osteogenic markers, mostly related to extracellular matrix [Nakashima et al., 2002]. Among the markers, Collagen I (Col1a1), Osteopontin (Opn), Bone Sialoprotein (BSP), and Alkaline Phosphatase (ALP) are detected.

Most Osterix positive cells in bone marrow are endosteal osteoblasts and subendosteal pre-osteoblasts [Nakashima et al., 2002]. There is a subpopulation of $0 \mathrm{sx}^{+}$cells that also expresses CXCL12/Stromal-Derived Factor-1 (SDF-1), which is crucial to HSC homing and lodging in the bone marrow cavity. Jung and colleagues [Jung et al., 2006] demonstrated in vitro that SDF-1 is secreted early in differentiation and gradually ceases as osteoblasts become mature. Greenbaum and colleagues (2013) and attempted to establish the role of different niches in the matter of SDF-1 secretion by the stromal population. SDF-1 gene selectively silenced in $0 \mathrm{sx}^{+}$ cells resulted in no significant changes in HSC frequency, as determined by both phenotypical and functional assays [Greenbaum et al., 2013]. However, hematopoietic progenitor cells retention in 


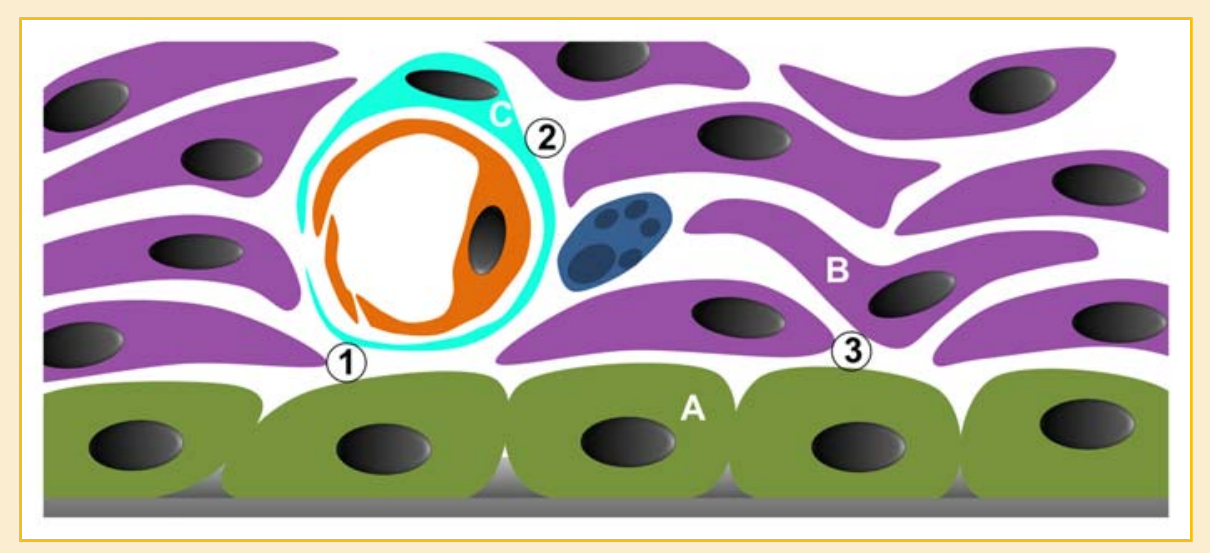

Fig. 2. Schematic magnification of the endosteal and subendosteal regions, which compose the endosteal niche. At least, three different stromal cell types can be identified in the niche: A, osteoblasts; B, non-perivascular reticular cells, probably mostly pre-osteoblasts; $C$, perivascular reticular cells, probably mesenchymal stem cells. These cells will organize the HSC niche. Three interfaces must be considered: 1, osteoblast and perivascular cells; 2, perivascular cells and pre-osteoblasts; and 3, osteoblasts and pre-osteoblasts. Each stromal combination will create a distinct niche for the same HSC pool. How this is organized and what is the dynamic among them is still unknown.

marrow was reduced, as CFU-C (Colony Forming Units in Culture) in blood and spleen increased in 10 and 8 fold higher, respectively [Greenbaum et al., 2013].

As pre-osteoblasts move forward in the differentiation path to mature osteoblasts, matrix protein synthesis is intensified. Osteocalcin is expressed by mature osteoblasts, which also express high levels of Collagen I (Col1a1), Osteopontin (Opn), Bone Sialoprotein (BSP), and Alkaline Phosphatase (ALP) [Aubin et al., 1995; Aubin, 1998]. Several surface markers, such as CD44, CD90, and ALCAM [Nakamura et al., 2010; Chitteti et al., 2013], and other molecular markers [Kiel et al., 2009; Greenbaum et al., 2013] have been used separately or in combination to fractionate subpopulations and to identify the hierarchical organization of the osteogenic lineage, or even their contributions to the hematopoiesis [Chitteti et al., 2010, 2014; Cheng et al., 2011], but still need some refinements.

Several in vivo models using genetically manipulated animals have been used to identify the contribution of different stromal cell types to HSC niche formation. However, so far, no specific marker has been credited the capacity to target one specific stromal population. From perivascular stem cells to differentiated osteoblasts, no described marker can be used to target one specific stromal population in the niche. However, stromal cells differences in this small ranged niche must not be ignored. Anatomical organization of the niche still is a very useful parameter.

\section{CONCLUDING REMARKS}

Current evidence supports the existence of two niches to harbor long-term HSC, referred as to "proliferative niche" and "quiescent niche" [Calvi et al., 2003; Zhang et al., 2003; Balduino et al., 2005; Wilson and Trumpp, 2006; Parmar et al., 2007; Taichman et al., 2010]. These niches comprise the perivascular cells and endosteal osteoblasts, respectively, and most of the data generated are based on HSC cell behavior, as they present the same phenotype in both niches in vivo. Although these two niches are usually discussed somehow disconnectedly, how far from each other are they in vivo? Apparently, blood vessels in the subendosteal region (perivascular niche) interface with the endosteal osteoblasts, leading to an idea of a multicellular niche rather than a single cell responsible for maintaining HSC. At some point, in the perivascular niche, HSC, at least part of them, will interact with perivascular cells and osteoblasts at the same time (Fig. 2). Besides, stromal cells residing neither in the perivascular niche nor on the bone surface must not be discarded, as they occupy a great extent of the subendosteal region.

Due to lack of specific markers to identify and categorize the stroma in this region, anatomical organization is very useful to better understand the interactions of the HSC within the niche and the identification of potential targets to manipulate and/or modulate HSC behavior. Besides, stromal cells in the endosteal niche may no longer be considered as a single "the endosteal stroma," as this will lead to misconception of what and how each cell contributes to the niche formation. Moreover, as HSC niche may also provide signals to support certain malignancies, to know the exact contributions from different stromal parties will be a way to identify targets and cure.

\section{ACKNOWLEDGEMENTS}

We must thank Professor Adriana Cesar Bonomo for her enthusiastic and provocative discussions, and support which inspired this prospect. This work was inpart supported by the Brazilian National Council for Scientific and Technological Development - CNPq, and the Carlos Chagas Filho Foundation for Research Support in Rio de Janeiro - FAPERJ (to A. Balduino); and by the National Cancer Institute (CA093900 to R.S. Taichman).

\section{REFERENCES}

Arai F, Hirao A, Ohmura M, Sato H, Matsuoka S, Takubo K, Ito K, Koh GY, Suda T. 2004. Tie2/angiopoietin-1 signaling regulates hematopoietic stem cell quiescence in the bone marrow niche. Cell 118(2):149-161. 
Aubin JE. 1998. Advances in the osteoblast lineage. Biochem Cell Biol 76:899-910.

Aubin JE, Liu F, Malaval L, Gupta AK. 1995. Osteoblast and chondroblast differentiation. Bone 17:77S-83S.

Balduino A, Hurtado SP, Frazão P, Takiya CM, Alves LM, Nasciutti L-E, ElCheikh, Borojevic MC. 2005. Bone marrow subendosteal microenvironment harbours functionally distinct haemosupportive stromal cell populations. Cell Tissue Res 319:255-266.

Balduino A, Mello-Coelho V, Wang Z, Taichman RS, Krebsbach PH, Weeraratna AT, Becker KG, de Mello W, Taub DD, Borojevic R. 2012. Molecular signature and in vivo behavior of bone marrow endosteal and subendosteal stromal cell populations and their relevance to hematopoiesis. Exp Cell Res 318:2427-2437.

Calvi LM, Adams GB, Weibrecht KW, Weber JM, Olson DP, Knight MC, Martin RP, Schipani E, Divieti P, Bringhurst FR, et al. 2003. Osteoblastic cells regulate the haematopoietic stem cell niche. Nature 425:841-846.

Lo Celso, Fleming C, Wu HE, Zhao JW, Miake-Lye CX, Fujisaki S, Côté J, Rowe D, Lin DW, Scadden CP. 2009. Live-animal tracking of individual haematopoietic stem/progenitor cells in their niche. Nature 457:92-96.

Cheng Y-H, Chitteti BR, Streicher DA, Morgan JA, Rodriguez-Rodriguez S, Carlesso N, Srour EF, Kacena MA. 2011. Impact of maturational status on the ability of osteoblasts to enhance the hematopoietic function of stem and progenitor cells. J Bone Miner Res 26:1111-1121.

Chitteti BR, Cheng Y-H, Streicher DA, Rodriguez-Rodriguez S, Carlesso N, Srour EF, Kacena MA. 2010. Osteoblast lineage cells expressing high levels of Runx2 enhance hematopoietic progenitor cell proliferation and function. J Cell Biochem 111:284-294.

Chitteti BR, Cheng Y-H, Kacena MA, Srour EF. 2013. Hierarchical organization of osteoblasts reveals the significant role of CD166 in hematopoietic stem cell maintenance and function. Bone 54:58-67.

Chitteti BR, Kobayashi M, Cheng Y, Zhang H, Poteat BA, Broxmeyer HE, Pelus LM, Hanenberg H, Zollman A, Kamocka MM, et al. 2014. CD166 regulates human and murine hematopoietic stem cells and the hematopoietic niche. Blood 124:519-529.

Ding L, Saunders TL, Enikolopov G, Morrison SJ. 2012. Endothelial and perivascular cells maintain haematopoietic stem cells. Nature 481:457-462.

Ducy P, Zhang R, Geoffroy V, Ridall AL, Karsenty G. 1997. Osf2/Cbfa1: A transcriptional activator of osteoblast differentiation. Cell 89:747-754.

Greenbaum A, Hsu Y-MS, Day RB, Schuettpelz LG, Christopher MJ, Borgerding JN, Nagasawa T, Link DC. 2013. CXCL12 in early mesenchymal progenitors is required for haematopoietic stem-cell maintenance. Nature 495:227-230.

Jung Y, Wang J, Schneider A, Sun Y-X, Koh-Paige AJ, Osman NI, McCauley LK, Taichman RS. 2006. Regulation of SDF-1 (CXCL12) production by osteoblasts: A possible mechanism for stem cell homing. Bone 38:497-508.

Kiel MJ, Iwashita T, Yilmaz OH, Morrison SJ. 2005. Spatial differences in hematopoiesis but not in stem cells indicate a lack of regional patterning in definitive hematopoietic stem cells. Dev Biol 283:29-39.

Kiel MJ, Radice GL, Morrison SJ. 2007. Lack of evidence that hematopoietic stem cells depend on N-cadherin-mediated adhesion to osteoblasts for their maintenance. Cell Stem Cell 1:204-217.

Kiel MJ, Acar M, Radice GL, Morrison SJ. 2009. Hematopoietic stem cells do not depend on $\mathrm{N}$-cadherin to regulate their maintenance. Cell Stem Cell 4:170-179.

Komori T, Yagi H, Nomura S, Yamaguchi A, Sasaki K, Deguchi K, Shimizu Y, Bronson RT, Gao YH, Inada M, et al. 1997. Targeted disruption of Cbfa1 results in a complete lack of bone formation owing to maturational arrest of osteoblasts. Cell 89:755-764.

Kuznetsov SA, Riminucci M, Ziran N, Tsutsui TW, Corsi A, Calvi L, Kronenberg HM, Schipani E, Robey PG, Bianco P. 2004. The interplay of osteogenesis and hematopoiesis: Expression of a constitutively active PTH/ PTHrP receptor in osteogenic cells perturbs the establishment of hematopoiesis in bone and of skeletal stem cells in the bone marrow. J Cell Biol 167:1113-1122.

Lambertsen RH, Weiss L. 1984. A model of intramedullary hematopoietic microenvironments based on stereologic study of the distribution of endocloned marrow colonies. Blood 63:287-297.

Logan AC, Weissman IL, Shizuru JA. 2012. The road to purified hematopoietic stem cell transplants is paved with antibodies. Curr Opin Immunol 24:640648.

Lord BI, Testa NG, Hendry JH. 1975. The relative spatial distributions of CFUs and CFUc in the normal mouse femur. Blood 46:65-72.

Morrison SJ, Scadden DT. 2014. The bone marrow niche for haematopoietic stem cells. Nature 505:327-334.

Morrison SJ, Uchida N, Weissman IL. 1995. The biology of hematopoietic stem cells. Annu Rev Cell Dev Biol 11:35-71.

Nakamura Y, Arai F, Iwasaki H, Hosokawa K, Kobayashi I, Gomei Y, Matsumoto Y, Yoshihara H, Suda T. 2010. Isolation and characterization of endosteal niche cell populations that regulate hematopoietic stem cells. Blood 116:1422-1432.

Nakamura-Ishizu A, Suda T. 2013. Hematopoietic stem cell niche: An interplay among a repertoire of multiple functional niches. Biochim Biophys Acta 1830:2404-2409.

Nakashima K, Zhou X, Kunkel G, Zhang Z, Deng JM, Behringer RR, de Crombrugghe B. 2002. The novel zinc finger-containing transcription factor osterix is required for osteoblast differentiation and bone formation. Cell 108:17-29.

Nilsson SK, Johnston HM, Coverdale JA. 2001. Spatial localization of transplanted hemopoietic stem cells: Inferences for the localization of stem cell niches. Blood 97:2293-2299.

Nombela-Arrieta C, Pivarnik G, Winkel B, Canty KJ, Harley B, Mahoney JE, Park S-Y, Lu J, Protopopov A, Silberstein LE. 2013. Quantitative imaging of haematopoietic stem and progenitor cell localization and hypoxic status in the bone marrow microenvironment. Nat Cell Biol 15:533-543.

Oguro H, Ding L, Morrison SJ. 2013. SLAM family markers resolve functionally distinct subpopulations of hematopoietic stem cells and multipotent progenitors. Cell Stem Cell 13:102-116.

Parmar K, Mauch P, Vergilio J-A, Sackstein R, Down JD. 2007. Distribution of hematopoietic stem cells in the bone marrow according to regional hypoxia. Proc Natl Acad Sci U S A 104:5431-5436.

Schofield R. 1978. The relationship between the spleen colony-forming cell and the haemopoietic stem cell. Blood Cells 4:7-25.

Seita J, Weissman IL. 2010. Hematopoietic stem cell: self-renewal versus differentiation. Wiley Interdiscip Rev Syst Biol Med 2:640-653.

Serafıni M, Dylla SJ, Oki M, Heremans Y, Tolar J, Jiang Y, Buckley SM, Pelacho B, Burns TC, Frommer S, et al. 2007. Hematopoietic reconstitution by multipotent adult progenitor cells: precursors to long-term hematopoietic stem cells. J Exp Med 204:129-139.

Siminovitch L, McCulloch EA, Till JE. 1963. The distribution of colony-forming cells among spleen colonies. J Cell Physiol 62:327-336.

Stein GS, Lian JB, van Wijnen AJ, Stein JL, Montecino M, Javed A, Zaidi SK, Young DW, Choi J-Y, Pockwinse SM. 2004. Runx2 control of organization, assembly and activity of the regulatory machinery for skeletal gene expression. Oncogene 23:4315-4329.

Stier S, Ko Y, Forkert R, Lutz C, Neuhaus T, Grünewald E, Cheng T, Dombkowski D, Calvi LM, Rittling SR, et al. 2005. Osteopontin is a hematopoietic stem cell niche component that negatively regulates stem cell pool size. J Exp Med 201:1781-1791.

Sugiyama T, Kohara H, Noda M, Nagasawa T. 2006. Maintenance of the hematopoietic stem cell pool by CXCL12-CXCR4 chemokine signaling in bone marrow stromal cell niches. Immunity 25:977-988. 
Taichman RS. 2005. Blood and bone: Two tissues whose fates are intertwined to create the hematopoietic stem-cell niche. Blood 105:2631-2639.

Taichman RS, Emerson SG. 1994. Human osteoblasts support hematopoiesis through the production of granulocyte colony-stimulating factor. J Exp Med 179:1677-1682.

Taichman RS, Emerson SG. 1998. The role of osteoblasts in the hematopoietic microenvironment. Stem Cells 16:7-15.

Taichman RS, Reilly MJ, Emerson SG. 1996. Human osteoblasts support human hematopoietic progenitor cells in vitro bone marrow cultures. Blood 87:518-524.

Taichman RS, Wang Z, Shiozawa Y, Jung Y, Song J, Balduino A, Wang J, Patel LR, Havens AM, Kucia M, et al. 2010. Prospective identification and skeletal localization of cells capable of multilineage differentiation in vivo. Stem Cells Dev 19:1557-1570.
Till JE, McCulloch EA. 1963. Early repair processes in marrow cells irradiated and proliferating in vivo. Radiat Res 18:96-105.

Till JE, McCulloch EA, Siminovitch L. 1964. A stochastic model of stem cell proliferation, based on the growth of spleen colony-forming cells. Proc Natl Acad Sci U S A 51:29-36.

Visnjic D, Kalajzic Z, Rowe DW, Katavic V, Lorenzo J, Aguila HL. 2004. Hematopoiesis is severely altered in mice with an induced osteoblast deficiency. Blood 103:3258-3264.

Wilson A, Trumpp A. 2006. Bone-marrow haematopoietic-stem-cell niches. Nat Rev Immunol 6:93-106.

Zhang J, Niu C, Ye L, Huang H, He X, Tong W-G, Ross J, Haug J, Johnson T, Feng JQ, et al. 2003. Identification of the haematopoietic stem cell niche and control of the niche size. Nature 425:836-841. 